Corrigendum

\title{
Corrigendum to "Autoimmune Hepatitis: Progress from Global Immunosuppression to Personalised Regulatory T Cell Therapy"
}

\author{
Nwe Ni Than, ${ }^{1,2}$ Hannah C. Jeffery, ${ }^{1}$ and Ye H. Oo ${ }^{1,2}$ \\ ${ }^{1}$ Centre for Liver Research and NIHR Liver BRU, University of Birmingham, Edgbaston, Birmingham B15 2TT, UK \\ ${ }^{2}$ Liver and Hepatobiliary Unit, University Hospital Birmingham National Health Service Foundation Trust, \\ Birmingham B15 2WB, UK \\ Correspondence should be addressed to Ye H. Oo; y.h.oo@bham.ac.uk \\ Received 22 September 2016; Accepted 12 October 2016 \\ Copyright (C) 2016 Nwe Ni Than et al. This is an open access article distributed under the Creative Commons Attribution License, \\ which permits unrestricted use, distribution, and reproduction in any medium, provided the original work is properly cited.
}

In the article titled "Autoimmune Hepatitis: Progress from Global Immunosuppression to Personalised Regulatory T Cell Therapy" [1], the word "adenosis" is misspelled in the legend of Figure 1 and should be corrected as "adenosine." The figure's legend is corrected as follows.

\section{References}

[1] N. N. Than, H. C. Jeffery, and Y. H. Oo, "Autoimmune hepatitis: progress from global immunosuppression to personalised regulatory T cell therapy," Canadian Journal of Gastroenterology and Hepatology, vol. 2016, Article ID 7181685, 12 pages, 2016. 


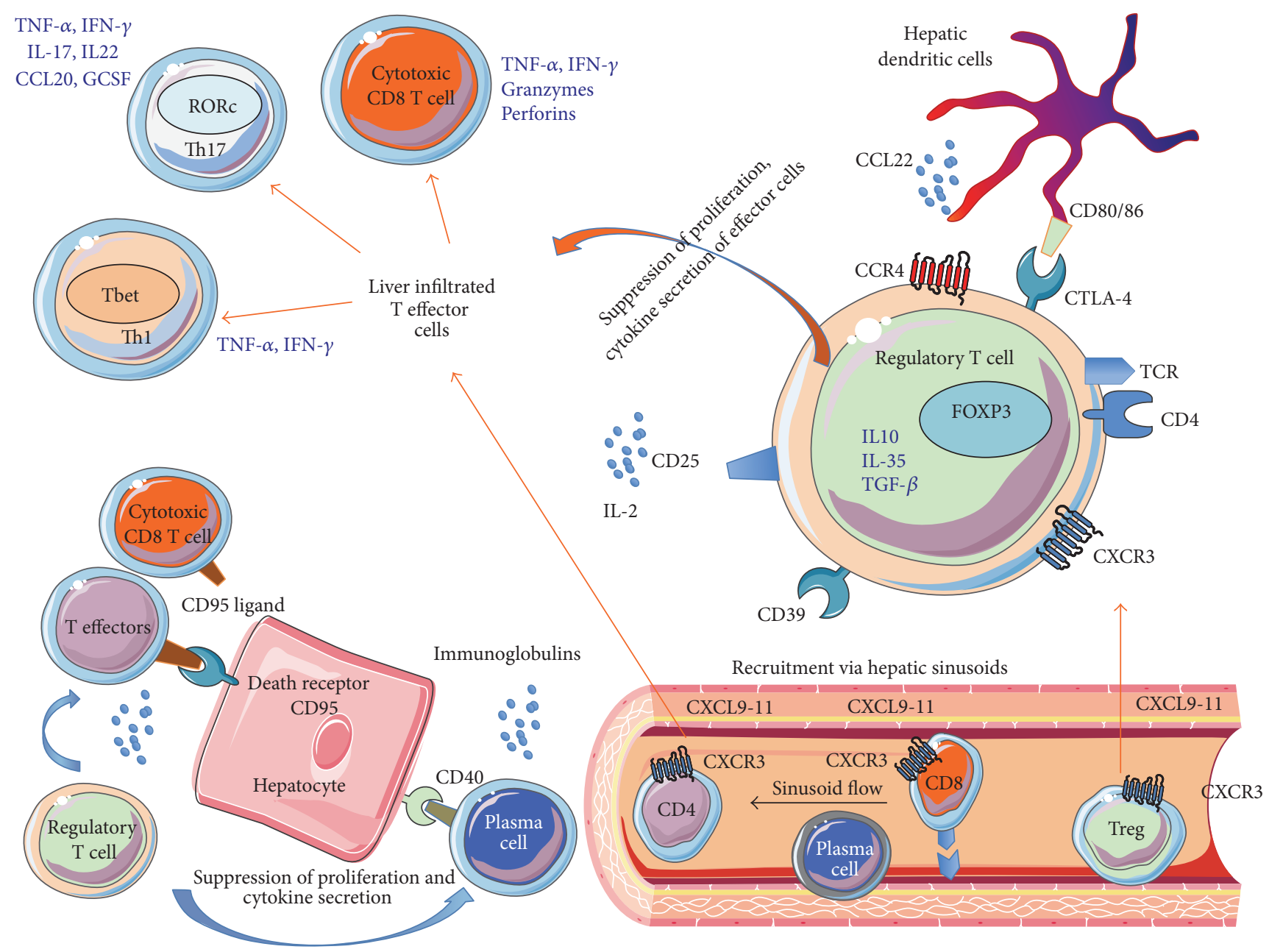

Figure 1: Pathogenesis of autoimmune hepatitis. Both effector T cells (CD4, CD8) and regulatory T cells (Treg) are recruited to inflamed autoimmune hepatitis liver via hepatic sinusoids. T effector cells lead to apoptosis of hepatocytes via CD95 ligand (dead ligand) expressed on them, which binds to CD95 on the hepatocytes. This killing action of T effector cells is regulated by regulatory T cells, which suppress proliferation and cytokine secretion of effector T cells. Plasma cells are also involved in immune-pathogenesis and they secrete immunoglobulin. Liver infiltrated T effector cells consist of Th17, Th1, and cytotoxic T cells. Th1 cells have $\mathrm{T}$ bet transcription factor; Th17 cells have transcription factor RORc. Cytotoxic T cells secrete IFN, TNF, granzyme, and perforins. Regulatory T cells $\left(\right.$ Treg $=$ CD4CD25 ${ }^{\text {high }}$ CD127 ${ }^{\text {low }}$ ) express liver tissue homing chemokine receptor CXCR3, which binds to its ligands CXCL9-11 expressed on inflamed hepatic sinusoid, hepatocytes, and bile ducts. Treg also expresses its functional markers CTLA4 (interacting with CD80/CD86 on dendritic cells). Dendritic cells secrete chemokine CCL22, which binds to chemokine receptor CCR4 on the regulatory T cells. CD39 on the Treg can generate immunosuppressive adenosine from ATP in the hepatic microenvironment. IL-2, which acts on its receptor CD25, is crucial for intrahepatic Treg survival and function. 


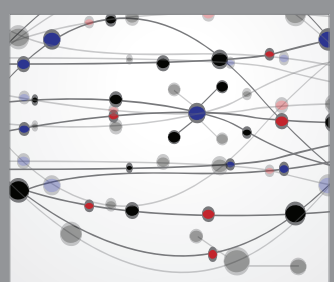

The Scientific World Journal
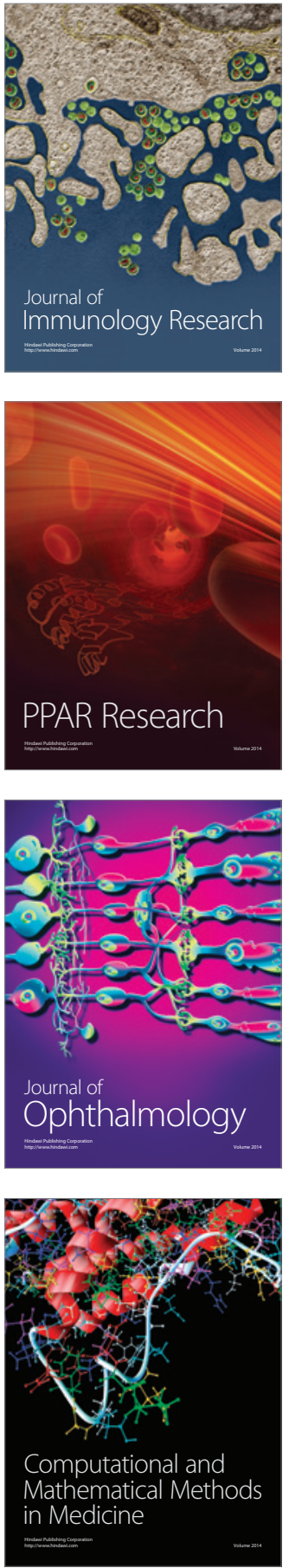

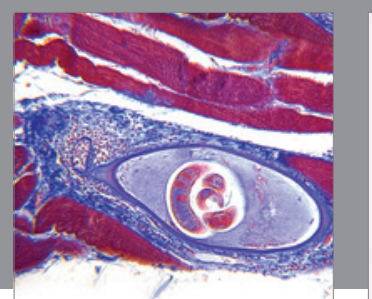

Gastroenterology Research and Practice

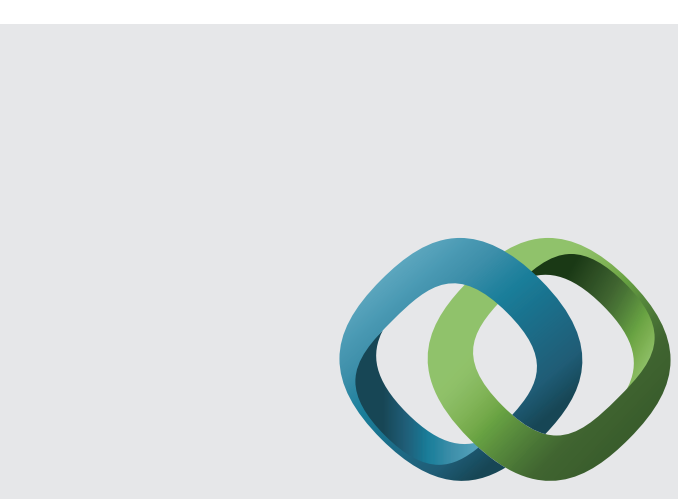

\section{Hindawi}

Submit your manuscripts at

http://www.hindawi.com
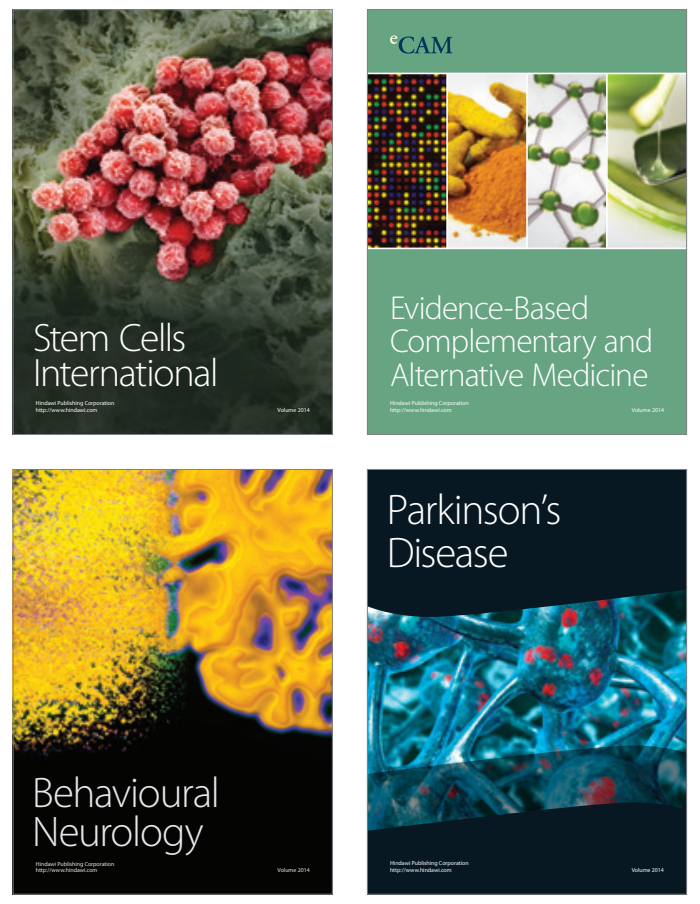
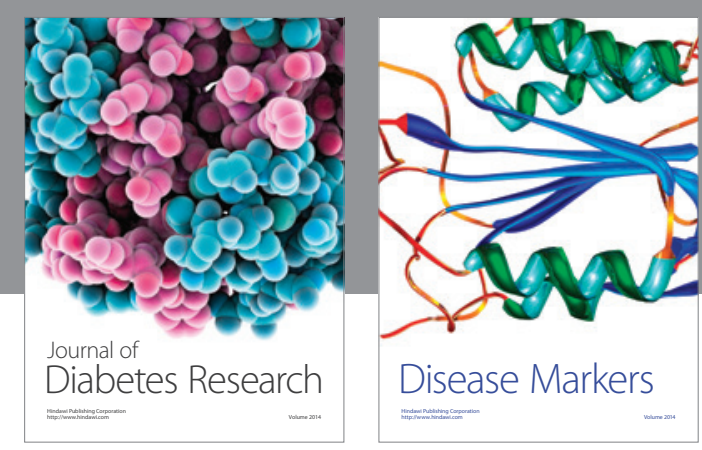

Disease Markers
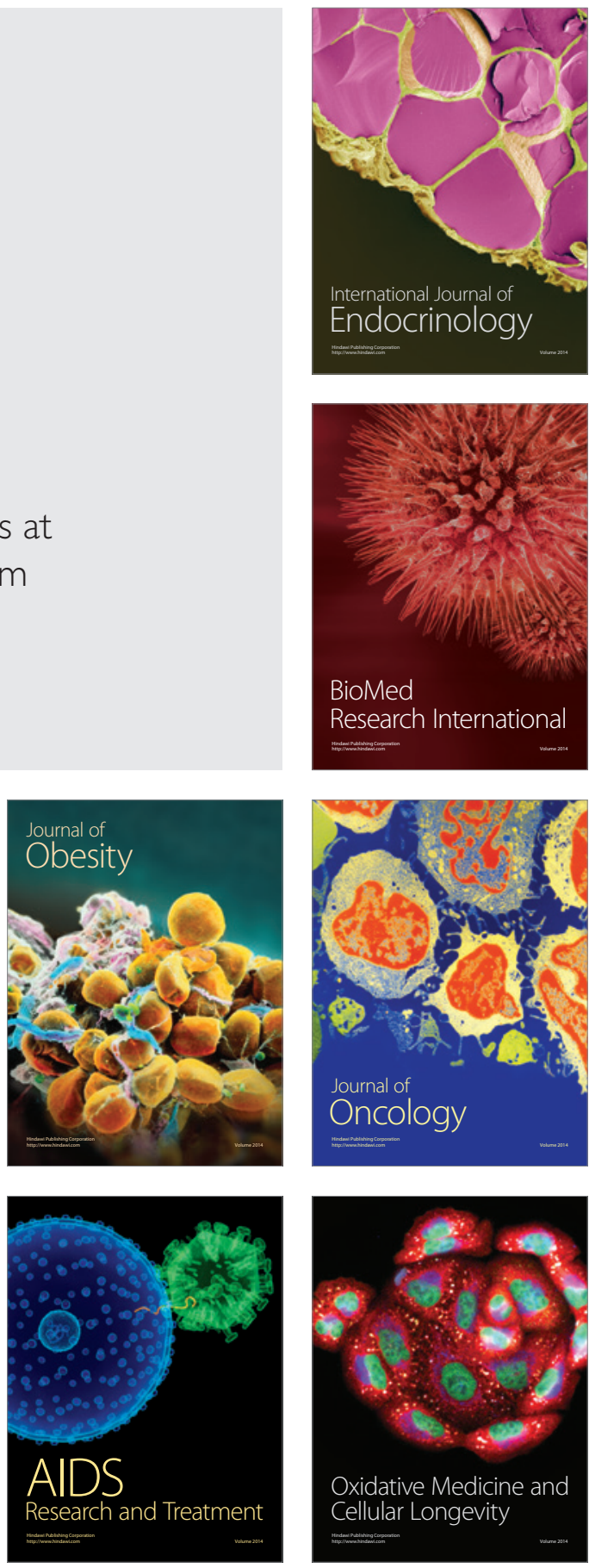